\title{
GCU
}

Glasgow Caledonian

University

University for the Common Good

\section{Analysis of uniformity of illumination of a freeform lens when combined with different optical sources}

Babadi, Sina; Ramirez-Iniguez, Roberto; Boutaleb, Tuleen; Mallick, Tapas Kumar

Published in:

Proceedings of SPIE: Optical Components and Materials XIII

DOI:

$10.1117 / 12.2209358$

Publication date:

2016

Document Version

Author accepted manuscript

Link to publication in ResearchOnline

Citation for published version (Harvard):

Babadi, S, Ramirez-Iniguez, R, Boutaleb, T \& Mallick, TK 2016, Analysis of uniformity of illumination of a freeform lens when combined with different optical sources. in S Jiang \& MJF Digonnet (eds), Proceedings of SPIE: Optical Components and Materials XIII. vol. 9744, 974417, SPIE, San Francisco, USA, pp. 974417. https://doi.org/10.1117/12.2209358

\section{General rights}

Copyright and moral rights for the publications made accessible in the public portal are retained by the authors and/or other copyright owners and it is a condition of accessing publications that users recognise and abide by the legal requirements associated with these rights.

Take down policy

If you believe that this document breaches copyright please view our takedown policy at https://edshare.gcu.ac.uk/id/eprint/5179 for details of how to contact us. 


\title{
Analysis of uniformity of illumination of a freeform lens when combined with different optical sources
}

\author{
Babadi S. ${ }^{a}$, Ramirez-Iniguez R. ${ }^{a}$, Boutaleb T. ${ }^{a}$ and Mallick T. ${ }^{b}$ \\ ${ }^{a}$ School of Engineering and Built Environment, Glasgow Caledonian Univeristy, Glasgow UK; \\ ${ }^{b}$ Environment and Sustainability Institute, University of Exeter, UK
}

\begin{abstract}
This paper presents the performance analysis of a freeform lens that can be used as a first or secondary optic when combined with a point or an extended light source. The light source can be an LED. The purpose of the optic is to increase uniformity of illumination within the footprint. The analysis is performed on the freeform lens when combined with: (i) an isotopic or a Lambertian point light source (ii) an isotropic or a Lambertian extended light source. This paper shows that through a design based on energy mapping between a light source and a target plane it is possible to achieve uniform illumination. The ZEMAX ray tracing simulation shows that the uniformity reduces gradually when the size of the light source increases. The results indicate that a freeform lens combined with a point source can generate over $95 \%$ uniformity.
\end{abstract}

Keywords: Freeform lens, energy mapping, isotropic and uniform illumination

\section{INTRODUCTION}

The use of Light-Emitting Diodes (LEDs) in illumination systems has become incredibly important. The LEDs are being used to displace traditional light sources due to their unique advantages: high flux efficiency, high reliability, low power consumption and long life. In addition they are considered to be environmentally friendly ${ }^{1}{ }^{2}$

In spite of its advantages, the light output from an LED generally produces a footprint with a higher intensity at the centre and a lower illuminance at the edges of the illuminated area $^{3} .{ }^{4}$ This poses a problem in some applications such as street lighting where illumination has to be uniform in order to satisfy national and international street lighting standards (e.g. EN 13201 part 1-5 (2013) and BS 5489). A variety of first or secondary optics with different configurations have been investigated to overcome of this problem. ${ }^{2}$

Parkyn W. ${ }^{5}$, for instance, proposed a segmented lens to provide uniform illumination with different patterns such as rectangular (for a rectangular target plane) for a flat and oblique luminaire placement. However, due to energy loss and difficulty in manufacturing this model with a faceted surface is not ideal for an illumination system.

Recently, Yan, X. et $\mathrm{al}^{6}$ designed an optic with reflective and refractive surfaces which when combined with an LED produces uniform illumination. As this optic is designed for a point source, it is necessary to increase the size of the optic considerably to keep uniform illumination for an extended light source.

This paper presents the analysis of uniformity of illumination provided by a freeform lens when a point source is replaced by an extended source. It also shows the effect of replacing an isotropic light source with a Lambertian one.

\section{DESIGN A FREEFORM LENS FOR AN ISOTROPIC POINT SOURCE}

The freeform lens does not have any predefined shape and the features of its profile depend on the following parameters: The spatial radiation pattern of the lighting device, the distance between the light source and the target plane, the size of an illuminated area. Several authors have discussed how to perform energy mapping for the creation of a free form lens ${ }^{78}$. Basically, certain amount of light flux is directed to specific sections of the target plane by refraction at the surface of the freeform lens. The shape of this optic is therefore created such that uniformity of illumination is achieved at the target plane.

B.S.: E-mail: sina.babadi@gcu.ac.uk 


\subsection{ZEMAX simulation results of a point source}

To investigate the performance of a freeform lens when combined with point sources, an isotopic point light source is placed at the centre of the optic. Both the optical source and the lens are input within the ray-tracing software. For this research the ray-tracing software used was ZEMAX. The ray tracing simulations are presented in Figure 1 and they show that the uniformity of illumination on the target plane achieved by the freeform lens is over $98 \%$.
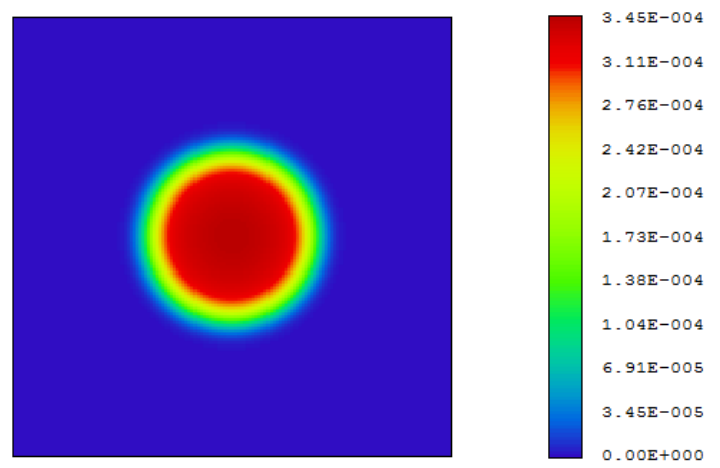

(a) Irradiance distribution on the target plane.

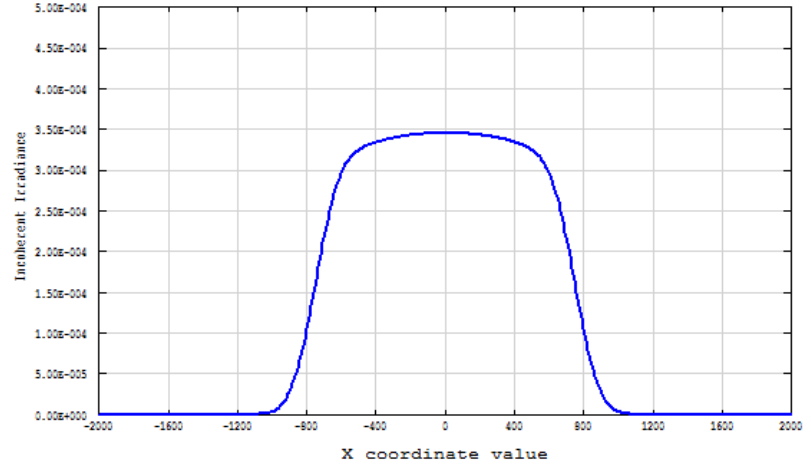

(b) Cross section of the light distribution on the target plane.

Figure 1. Over $98 \%$ uniformity of illumination can be achieved when combining the freeform lens with an isotropic point light source.

When the isotropic point light source is replaced by a Lambertian one, uniformity deteriorates. Figure 2 shows that in this case, there is higher light intensity at the centre of the footprint, and lower intensity at the edges of the footprint on the target plane.
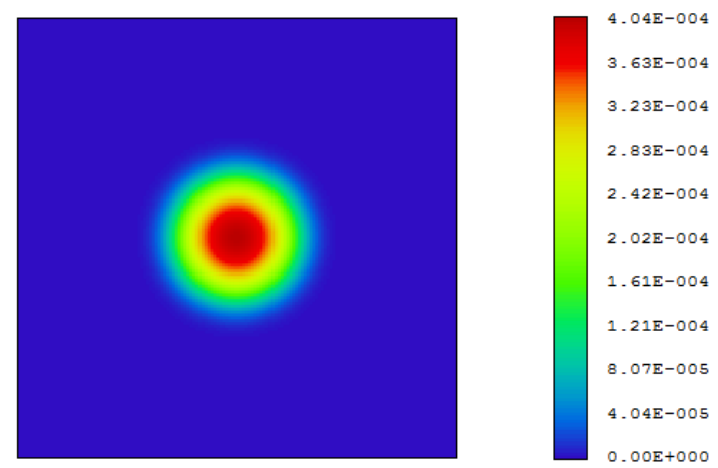

(a) Irradiance distribution on the target plane.

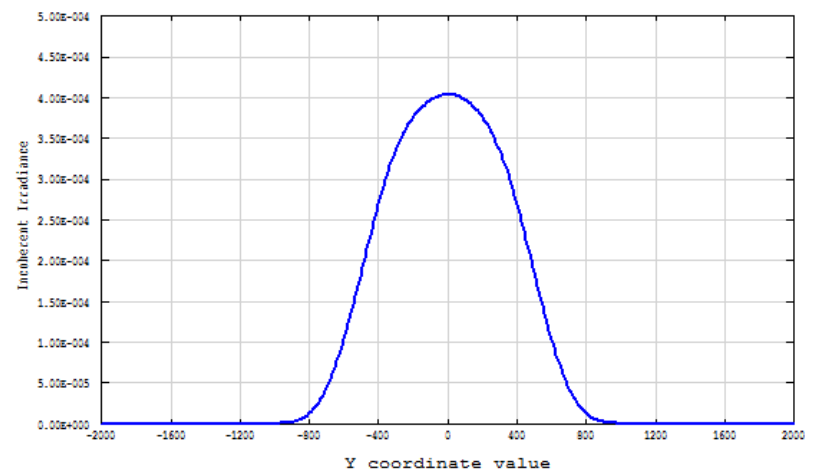

(b) Cross section of the light distribution on the target plane.

Figure 2. Illumination from a point source with Lambertian pattern when combined with a freeform lens.

\subsection{Design freeform lens for a Lambetian point source}

The algorithm to design a freeform lens can be modified by taking into account that the power emitted by the point source is not constant in all directions, but that it has a Lambertian emission pattern instead. This will define the new geometry of the freeform lens required to perform the energy mapping. Figure 3 compares two energy mappings for (a) an isotropic light source and (b) a Lambertian light source. The refracted ray $J_{1}$ after refraction on the surface of the lens reaches the desired point $T_{1}$ on the target plane. 


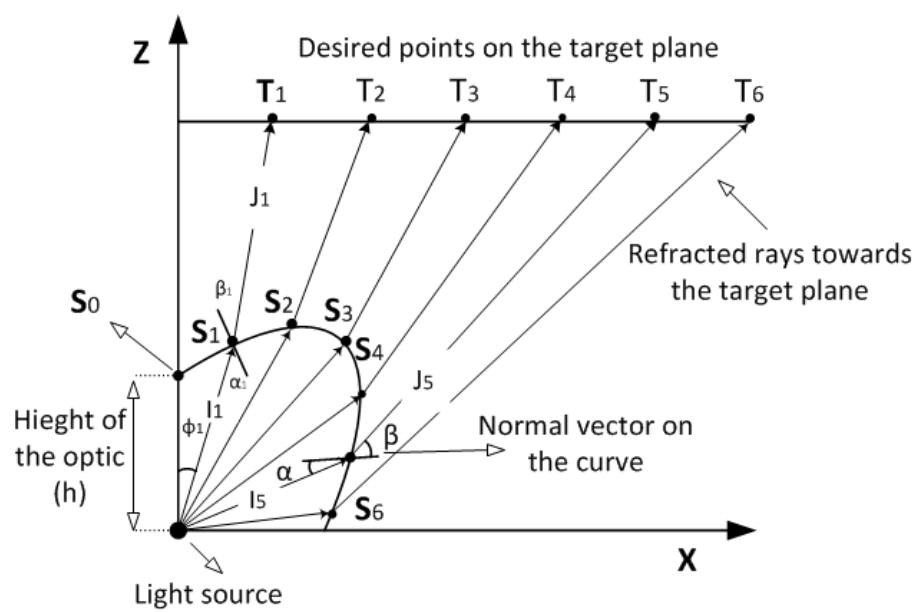

(a) For an isotropic light source.

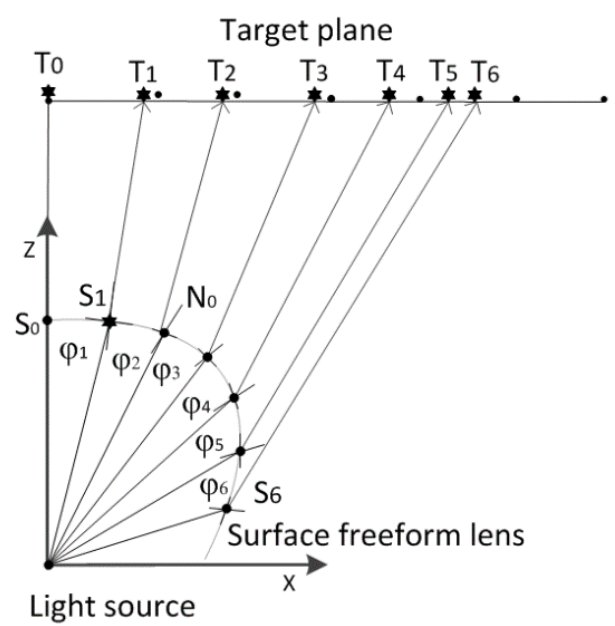

(b) For a Lambertian source

Figure 3. Schematic ray tracing of the freeform lens

Figure 4 shows that if the freeform lens is designed to satisfy these conditions it is still possible to maintain a uniformity of over $98 \%$.
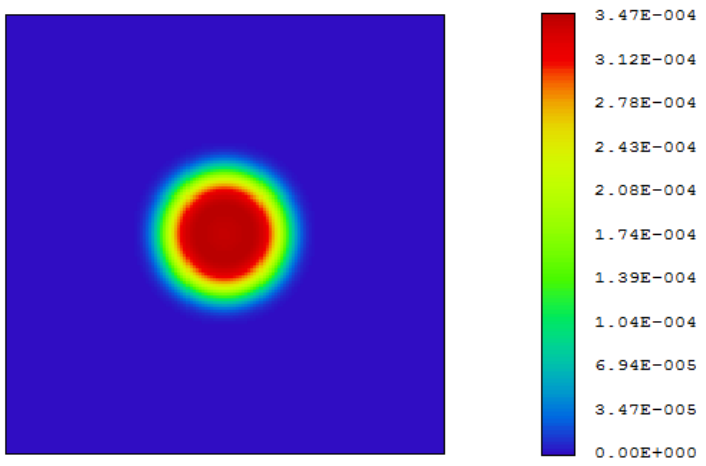

(a) Irradiance distribution on the target plane.

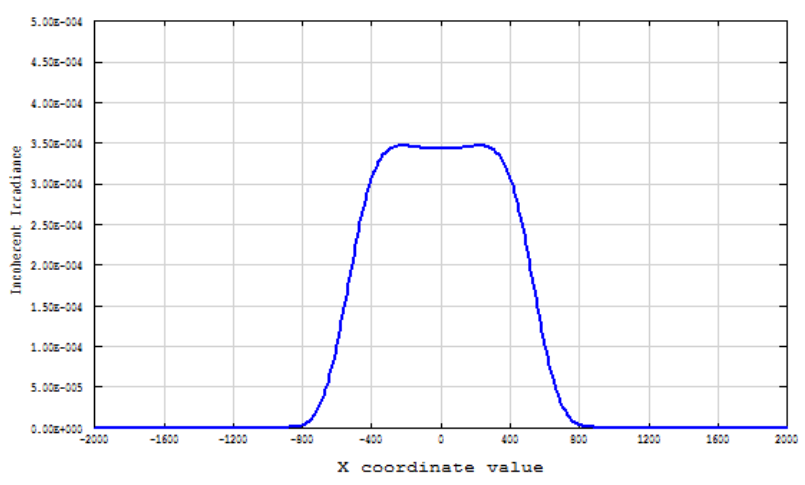

(b) Cross section of the light distribution on the target.

Figure 4. Results from the ray tracing simulations when the isotropic point light source is replaced with a Lambertian one and the freeform lens optimised for it.

When using the Lambertian light source the illumination area is smaller compared to the one produced by an isotropic light source in order to keep the level of illumination uniform at the target plane. The consequence of modifying the shape of the freeform lens for a Lambertian point source is that the radius of the illuminated area reduces from $870 \mathrm{~cm}$ to $600 \mathrm{~cm}$ as shown in Figures 1 and 4 respectively.

\section{EFFECTS OF USING AN EXTENDED SOURCE}

The design algorithm of freeform lenses normally assumes that the light source is a point. However, when a real source with specific dimensions is use to replace the point source the uniformity decreases. Figure 5 shows that the irradiance within the circular area (the footprint) at the target plane decreases at the centre and that there is a gradual decrease of uniformity at the edges of the footprint. In this example a freeform lens with $3 \mathrm{~cm}$ height has been combined with a circular light source with $1.4 \mathrm{~cm}$ diameter with Lambertian radiation pattern. As a 
results of this the uniformity of illumination reduces to $81 \%$, which means that only $23 \%$ of the illumination area contains uniform illumination.
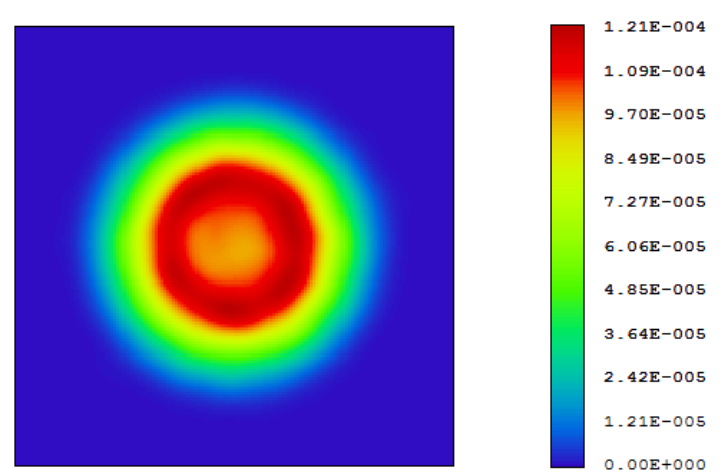

(a) Illumination on the target plane.

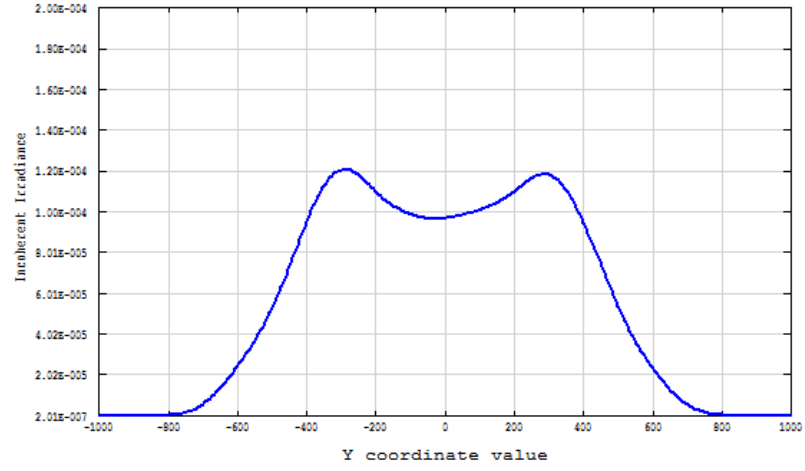

(b) Cross section of the light intensity on the target plane.

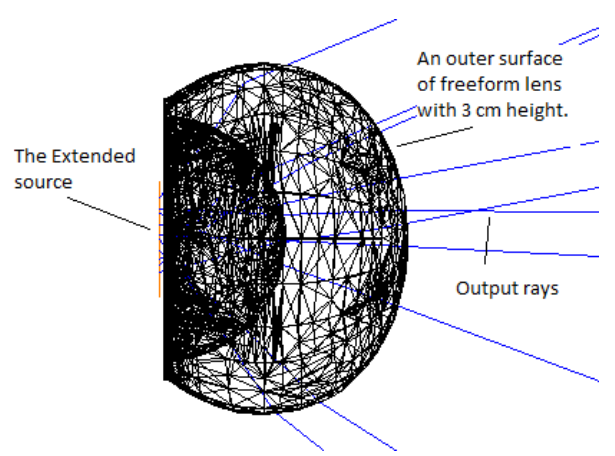

(c) Illumination system comprising of an 1.4

$\mathrm{cm}$ diameter LED and a freeform lens.

Figure 5. Illuminance distribution from an extended source when combined with a freeform lens.

To shows the effect of increasing the size of the extended light source on the uniformity, the size of the LED at the centre of the freeform lens has been gradually increased. Figure 6 (a) shows how the uniformity decreases steadily when the size of the light source increases. Figure 6 (b) compares the percentage of the footprint area that contains uniform illumination to that of the total footprint area. Here it can be seen that as the size of the LED increases the portion of the footprint within which illuminance is uniform decreases.

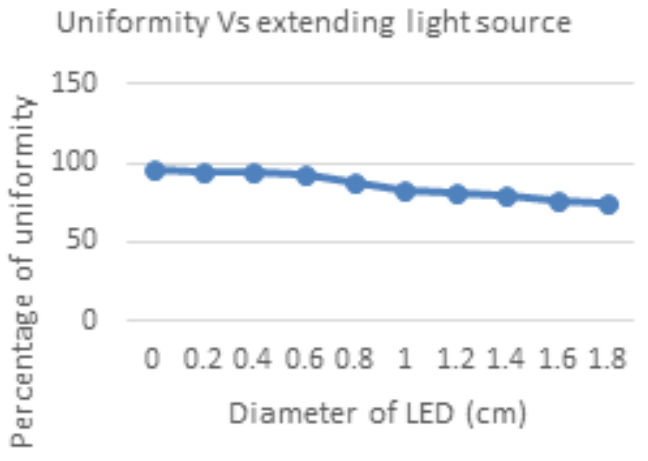

(a) The percentage of uniform illumination area compared to whole illuminated area decreased rapidly by increasing the size of the light source.

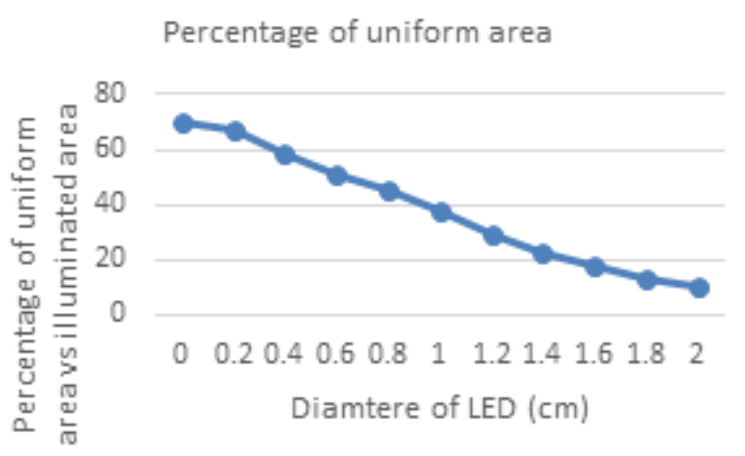

(b) Percentage of uniformity has been decreased by increasing.

Figure 6. Effect of the increasing the size of the light source. 


\subsection{How to improve uniformity by the extended source}

There are two methods available to improve uniformity of the freeform lens with the extended light source. The first method consist of increasing the size of the optic compared to a light source: (a) using a smaller size of LED: for practicality it is possible to use a high power LED with a small size. (b) Using a bigger lens: This method scales up the size of lens in which the extended source acts as an approximate point source. In order to have an optical system where the source of illumination behaves like a point source, the diameter of the freeform lens needs to be at least 5 times larger the diameter of the optical source. It is important to consider the effect that scaling the lens up has on the uniformity.

Figure 7 shows how extended sources damage uniformity. A surface of lens has been designed only for rays coming from a point source at the bottom-centre of the optic and therefore it cannot handle other rays from other section of the extended light source. As it can be seen from Figure 7 (a) the ray 2 emitted from the centre and the rays 1 and 3 emitted from the edges of the extended source, these three rays converge onto one point of the surface of the freeform lens after which they are refracted onto different points of the target plane. This means that only ray 2' reaches the desired point on the target plane. This results in non-uniform illumination.

However this situation can been improved as shown in Figure 7 (b) by increasing the size of the optic relative to the light source.

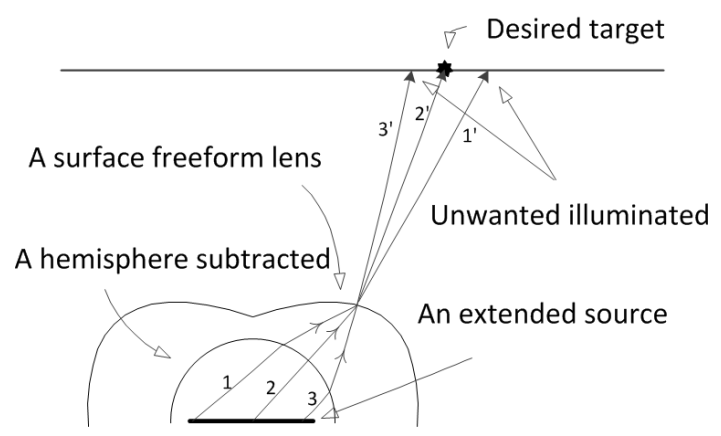

(a) An extended source combined with a freeform lens.

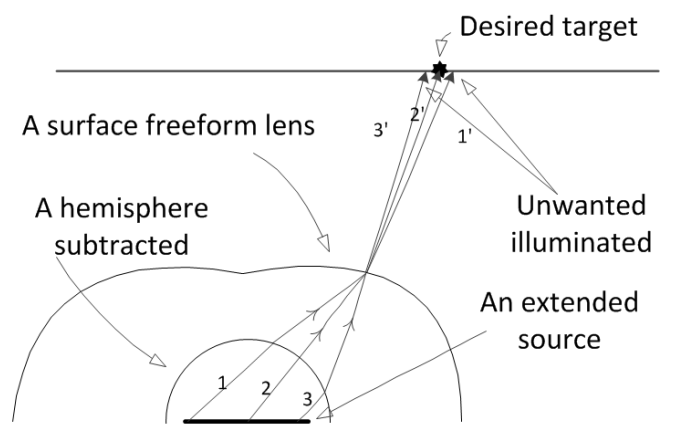

(b) Effect of increasing size of the freeform lens to reduce the effect of the light source dimensions.

Figure 7. Schematic view of the ray tracing of an extended source.

An alternative method to optimise the uniformity of illuminance at the target plane is by changing the freeform lens geometry: Uniformity can be increased by using an iterative algorithm based on rearranging the output rays that reach the target plane.

\section{CONCLUSIONS}

A freeform lens design process based on the energy mapping between the target plane and the lens can be used to achieve uniform illumination within the target plane. This paper has presented the analysis of the performance of a freeform lens when combined with different sources of illumination. The ZEMAX simulations demonstrate that over $95 \%$ uniformity can be achieved when the optic is used with a point source whether this is isotropic or Lambertian. However, when the light source is extended it is necessary to change the size ratio between the source and the lens or to reshape the freeform lens to compensate for the large area effect of the source of illumination.

\section{ACKNOWLEDGMENTS}

This research was sponsored by the Energy Technology Partnership (ETP), Optical Antenna Solution (OAS) and Glasgow Caledonian University. 


\section{REFERENCES}

[1] Kim, B., Choi, M., Kim, H., Lim, J., and Kang, S., "Elimination of flux loss by optimizing the groove angle in modified fresnel lens to increase illuminance uniformity, color uniformity and flux efficiency in led illumination," Optics express 17(20), 17916-17927 (2009).

[2] Jiang, J., To, S., Lee, W., and Cheung, B., "Optical design of a freeform tir lens for led streetlight," OptikInternational Journal for Light and Electron Optics 121(19), 1761-1765 (2010).

[3] Ding, Y., Liu, X., Zheng, Z.-r., and Gu, P.-f., "Freeform led lens for uniform illumination," Optics Express 16(17), 12958-12966 (2008).

[4] Babadi, S., Ramirez-Iniguez, R., Boutaleb, T., and Mallick, T., "Performance analysis of a dtirc-led illumination structure," in [Optics and Measurement Conference 2014], 944205-944205, International Society for Optics and Photonics (2015).

[5] Parkyn, W. A., "Illumination lenses designed by extrinsic differential geometry," in [International Optical Design Conference], 389-396, International Society for Optics and Photonics (1998).

[6] Yan, X., Yang, J., Bu, F., and Zhang, G., "A novel led lens for rotationally symmetric uniform illumination," in [Electronics and Optoelectronics (ICEOE), 2011 International Conference on], 3, V3-82, IEEE (2011).

[7] Wu, D., Wang, K., and Liu, S., "Freeform lens design for uniform illumination with extended source," in [Electronic Packaging Technology and High Density Packaging (ICEPT-HDP), 2011 12th International Conference on], 1-5, IEEE (2011).

[8] Chen, J.-J., Wang, T.-Y., Huang, K.-L., Liu, T.-S., Tsai, M.-D., and Lin, C.-T., "Freeform lens design for led collimating illumination," Optics express 20(10), 10984-10995 (2012). 